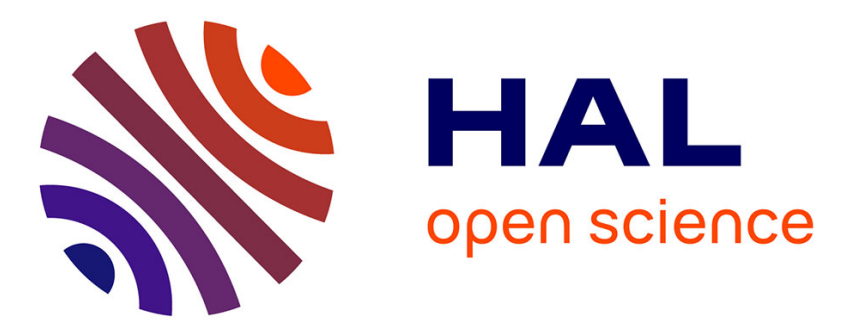

\title{
Situation Awareness for Effective Production Control
}

Andreas D. Landmark, Emrah Arica, Birgit Kløve, Pål Furu Kamsvåg, Eva Amdahl Seim, Manuel Oliveira

\section{To cite this version:}

Andreas D. Landmark, Emrah Arica, Birgit Kløve, Pål Furu Kamsvåg, Eva Amdahl Seim, et al.. Situation Awareness for Effective Production Control. IFIP International Conference on Advances in Production Management Systems (APMS), Sep 2019, Austin, TX, United States. pp.690-698, 10.1007/978-3-030-30000-5_84. hal-02419241

\section{HAL Id: hal-02419241 \\ https://hal.inria.fr/hal-02419241}

Submitted on 19 Dec 2019

HAL is a multi-disciplinary open access archive for the deposit and dissemination of scientific research documents, whether they are published or not. The documents may come from teaching and research institutions in France or abroad, or from public or private research centers.
L'archive ouverte pluridisciplinaire HAL, est destinée au dépôt et à la diffusion de documents scientifiques de niveau recherche, publiés ou non, émanant des établissements d'enseignement et de recherche français ou étrangers, des laboratoires publics ou privés. 


\title{
Situation Awareness for Effective Production Control
}

\author{
Andreas D. Landmark, Emrah Arica, Birgit Kløve, Pål Furu Kamsvåg, Eva Amdahl \\ Seim, Manuel Oliveira \\ SINTEF Digital, Department of Technology Management, Trondheim, Norway \\ \{andreas.dypvik.landmark | emrah.arica | birgit.klove | \\ paal.f.kamsvaag | eva.amdahl.seim | manuel.oliveira\}@sintef.no
}

\begin{abstract}
Situation awareness is a growing need for manufacturing operators with the digital transformation of manufacturing environments where operators are expected to take larger responsibilities and tasks on the production flow. To make effective production control decisions, workers need to be aware of the situation that consists of multiple factors such as the production status, and internal and external demand requirements. Adapting existing models for situation awareness, this paper presents four case examples of manufacturing companies that implement digital technologies for situation awareness.
\end{abstract}

Keywords: Situation Awareness, Production Control, Manufacturing Industry.

\section{Introduction}

Most of the modern manufacturing companies operate in complex and dynamic organizations composed of equipment, people, information and information systems, which are influenced by a multitude of internal and external factors. In such complex environments, the decision makers often lack the holistic view of the situational factors, which leads to suboptimal local decisions and actions [1]. Earlier work [2] has attempted to apply the situational awareness framework of Endsley and Garland [3] in order to describe and understand operators need for data and information in their decision-making on the shop floor. Situation awareness (SA) is "the perception of the elements in the environment within a volume of time and space, the comprehension of their meaning and the projection of their status in the near future" [4]. This relates back to classic decision-making theory to the more recent frameworks for describing workspace awareness [5]. In workspace awareness, there is the recognition that awareness in personalized technology, such as the personal computer, and the need for "groupware" in order to collaborate virtually.

In the highly automated and digitalized factories of the future, operators will have fewer physical tasks, but more decision making and problem-solving tasks. Today's information systems mainly address the higher-level decision makers such as planners' needs, while there is a certain gap for decision support on the shop floor. In line with Industry 4.0 thinking, the idea was that technology can enhance and extend the human abilities in production control - and in the most advanced form the tightly integrated cyber-physical system of production machine and operator. However, the impetus in 
Industry 4.0 has been heavy on the technologies and has less focus on the softer side of enhancement. Nevertheless, true SA only exists in the mind of the human operator. Data does no good unless it is successfully transmitted, absorbed and assimilated in a timely manner by the human to form SA [6]. This shortcoming has previously been described at length within the computer-supported collaborative work field [7]. While the idea was that media-rich shared spaces would foster comprehension and projection; it often fails to do either.

With the introduction of more personalized technology on the shop floor, going from collective-by-design solutions such as whiteboards and various KANBAN solutions to individual-by-design solutions such as smart glasses or smart watches - this mirrors the development in the office. The need for industrial groupware - to support coordination and collaboration when hardware by design is non-inclusive and lacks the option for physical collaboration between users. While SA in manufacturing is an emerging topic receiving interest from academia in recent studies, there is a research gap in investigating the practical applications of technologies providing SA to operators. In this study, we have attempted to explore how SA of operators is supported in manufacturing companies, through four cases of technology for operative production control.

\section{Situation Awareness (SA) in Manufacturing}

SA has been coined into the literature by aviation researchers fails [8], studying the cognitive tasks of aviation practitioners, and then have been spread to numerous application areas and work environments, including manufacturing. A central SA concept in the manufacturing context is the level of automation (LOA) that aims to provide various levels of support to the operators [9], depending on their task. Identifying and using various types of support is needed to avoid the potential out-of-the-loop performance problem (OOP) which refers to the slow intervention of operators when automation fails [8]. Following types of support are identified for SA of operators.

\section{$2.1 \quad$ Perception support}

Perception-support is at the core of Endsley's model, the basic ability to perceive and be aware of processes in your environment. At the basics, perception support can be measurement equipment (e.g. thermometers, calipers) that allows the operator to observe physical quantities more precisely - or observe quantities not visible to the human eye (e.g. radiation). With connected digital sensors, perception support also includes teletranslation, i.e. that one can observe quantities not directly in the local environ or inaccessible due to hazards (inside operating machinery). However, basic focus on the data accessibility from multiple sources lead to information intensive unmanageable complexity for the operator with the increasing complexity of production environments [10]. For an efficient perception support, cognitive standpoint should be taken to integrate the required information with operator's cognitive tasks [11]. 


\subsection{Comprehension support}

At the next level, putting physical observations or quantities into context requires the ability to comprehend the values. This requires knowledge of the manufacturing context on the operator. The context model of the operators in manufacturing consists of several elements; the context model of the operators built according to the operational (e.g. process, task), organizational (e.g. the team that operator belongs to) and usercentric (e.g. competency profile of the operator) dimensions of context [12]. Or a more extended context model, including the environmental (e.g. outdoor conditions) and system (e.g. devices) dimensions [13]. For some processes, it is also necessary with comprehension support due to complex causality or similar. For example, handling unexpected events in production control in a timely and appropriate manner require that operators comprehend the cause, impact, and context of the event [1]. Such support is traditionally available through control-room systems where a mathematical model or simulation is conducted on the sensor data before results are presented to the operator. One can see a similar use of statistical process control charts [14], which is a manual tool for putting measurements into a monitoring and control context.

\subsection{Projection support}

At the highest level of Endsley's SA model, the ability to not only reason over the current state, but also over the project measurements and observations into a future state given the current comprehension [3]. This requires predictive power in the causality relations that underlie the comprehension support. Predictive Situation Awareness in manufacturing can benefit from artificial intelligence (AI) methods that can enable reasoning methods to estimate current situations as well as to predict future situations [15]. Nevertheless, most AI methods are tested for limited use case scenarios. In real world applications, where the situation is far more complex, the prediction accuracy is still a critical issue to be solved for the implementation success of such methods.

\subsection{Coordination support}

In all processes where there are interdependencies between tasks or products, where multiple workers must work together to achieve overall quality or flow - there is a challenge in coordinating the production. Cooperative work involves many interdependencies, effective management of these interdependencies - i.e. coordination - is pivotal [16]. The traditional way of managing coordination in manufacturing is standardization of work and procedures. Takt time is one way of also standardizing the flow of work in manufacturing. However, in production mixes where takt is infeasible other forms of coordination are necessary. Many of which, requires perception, comprehension and projection of the situation of colleagues onto your own situation. Therefore, improving awareness by increasing the visibility of information's through technology is important means for support coordination. 


\subsection{Collaboration support}

Collaboration may be defined as “departments' willingness to work together, whereby they share resources and understand and have consensus on common vision and goals.” [17]. It is now possible to realize collaborative work and SA from technological point of view, however there are still big gaps from human factors point of view [18]. Collaboration requires more than cooperative work; it is necessary to do master the mutual adjustment and trade-offs of cooperative work - but for true collaboration it requires even more streamlined production and closer collaboration between members of the value chain in order to achieve efficiency and smooth flow through the dependencies between each process steps [19].

\section{Case Examples}

In this paper, case study research methodology has been applied to study, exemplify, and validate the research constructs drawn in section 2. Case companies have been selected from ongoing or completed industry-driven research projects focusing on digitally enhancing the manufacturing operators' tasks. The three of the cases are collected from production companies in Norway, all of which at the corporate level have turnovers in excess of \$100 MUSD and operate in a primary export-oriented global market. All three have processes involving metal-work and machining operations. The last case is collected from European companies involved in an EU project. The authors have worked with the companies over years - both in development, implementation and evaluation of technological as well as organizational solutions for operator productivity and efficient production. This collaboration has enabled accessibility to rich data from companies. The primary empirical data source has been workplace observations and semi-structured interviews with the operators. Enterprise data and documentation (e.g. production data from ERP system) have also been collected and analyzed.

\subsection{Case I: Tablets connected to the control system on each machine}

The case company has implemented a manufacturing analytical solution called Vimana on the tablets located at the CNC-control system for six of their machines at the department of cutting heads. In this department, each operator runs two machines simultaneously. The analytical software provides visibility and deep insight into the machinery performance, for all of the six machines. The operators obtain a good indication of machine status by taking a quick glance at the tablets. Information on key figures, such as machine stops, production time, and amount of production over the last few hours, with relevant, actionable data are provided. This increases situational awareness of the operators, enabling better planning, problem solving, and execution so that assets are optimized, work is simplified, and a data-driven culture is adopted. Using these tablets, the operators have built a stronger team feeling internally in the cutting head department. They work together towards common production goals and assist each other if downtime on the various machines occur. Furthermore, the operators move orders between machines in case of downtime or absenteeism of colleagues. 
However, worth noting, changes in the production site require a good implementation process and great leadership. This is especially true in a change process where new digital tools can be used as a mean for surveillance, which is a well-known problem when implementing digital technology for collecting and sharing data. During the introduction of the tablets, some operators expressed their concerns, fearing that this digital solution would contribute to increased surveillance and not lighten their workday as intended. It could be argued that this happened as a result from weak leadership and a poorly managed implementation process. The management did not sufficiently inform the operators before implementation. Now, one year later, most operators are far more positive. They have realized that the tablets are implemented in order to support them in their workday by providing important and useful information, and as a result, the tablets have contributed to significant productivity gains for the department.

\subsection{Case II: Computers on each working station with software-solution for production planning}

The case company developed their own production planning tool and made it readily available to all operators in production. The idea behind the software was for it to act as a replacement for mainframe systems, where one could control production orders and sales orders. The company wanted to place computers in the production, so that the operators themselves could plan their own working day and be able to optimize the production orders and attain visual control over the queue on their machine. The system is used to obtain all kind of information regarding different orders. The operators can find information on each order, such as 3D models, drawings, specifications, production priority, delivery deadline, raw materials and inventory, picking list, production statistics, reasons for previous wrecks, the load on the various machines, production deviations, and the value chain for each order. The operators can keep track of where each order is located, and whether the order is in working progress in the relevant step in the value chain. They can find order history, such as deviation history and production details, related to specific orders. This kind of information is often very valuable and facilitates work. The system displays the order list by priority. When priority order changes, for example as a result of an urgent delivery, the information is updated.

The system also shows the planned workload on each machine in the coming weeks, so that the operator can facilitate optimal planning of his own working week. If a machine has a lot of queue, it is possible for the operators to coordinate between themselves and move orders to other machines with less workload. The planning phase is largely entrusted to the operator and the operator actively uses the information from the system into the planning phase to make everything ready for the production phase. The system is based on transparency. All information is available to everyone in the company, and this is highly valued among the employees. The operators appreciate the fact that that the software is made in-house considering that both operators, planners and designers can continuously propose new features and enhancements to make the system more customizable to display the information they need in their workday. However, as the system can continuously be developed, there is a danger of a user interface which becomes less user-friendly and messy as a result of information overload. 


\subsection{Case III: Production Control events delivered to smart watch}

The case company has a factory wide machine monitoring solution, that monitors OEE and similar metrics for all CNC machines and machine control. This is a partly custom solution, tightly integrated with the maintenance scheduling system, allowing operators to view the operational status of all machines live. This is also used for calculating and showing key performance indicators in various dashboards. Parts of the production is based on multiple machines per operator, hence certain parts are machined with the machines running un-attended. However, operators are on hand (covering a pool of machines) to address any unforeseen events or stops in the programs. When covering multiple machines, the ability to perceive and project future states becomes a challenge requiring good short-term memory skills and mental capacity to be able to balance and coordinate their own workload. Unforeseen events cause loss of productivity with machines remaining idle until the fault is corrected. To support the workers in addition to more traditional "traffic lights" indicating machine status, visible from a distance, the company extended their production control system with a smart-watch interface that allows certain messages to be pushed to individual operators. This includes projection cues such as " 15 minutes remaining in program" to the more perception aiding messages such as "Machine [X] stopped due to [Y]". This reduces time-to-discovery of unforeseen stops, and ideally also aids the operator's ability to plan and self-coordinate.

\subsection{Case IV: Knowledge in Time, an industrial Augmented Reality solution for the operator on the shopfloor}

The Knowledge in Time (KIT) service aims to provide cognitive support tailored to the needs of each individual operator. The KIT service has been deployed at three endusers covering a range of different industries, namely aeronautics, robot manufacturing and furniture manufacturing. Each of the end-users has differing production rates and product/process complexities, which have their own challenges:

Furniture Manufacturing: The primary use of the system is for training purpose of the operators. However, the system is also used by the experienced operator by bringing to their attention intricacies of the assembly operation based on their past performance and evidence of retention concerning process. The secondary use of the system is to verify the quality of the training and decide on potential workplace optimization.

Robot Manufacturing: The system provides step-by-step instruction support, whilst monitoring the operator's activities to assess the quality of their work and capturing evidence of the work. The secondary use of the captured data is to support quality auditing of the production process.

Aeronautics: The system supports the operators by indicating the most common process mistakes incurred in the recent past. The system in this case monitors the operator's actions and indicates the error probability in the task, thereby bringing to the attention of the operator. The secondary use of the system is to improve the process optimization.

The operators have appreciated the use of augmented reality with machine learning to increase their cognitive capabilities tailored to the particular context of work being carried out. However, the secondary use of the system to support long-term cycle provides the means to augment and improve existing company knowledge. 


\section{$4 \quad$ Discussion and Conclusion}

This paper has investigated the topic of SA in the manufacturing context. The case examples for SA support from real manufacturing companies are summarized in Table 1. Referring to the research gap stated in Section 1, we see that the emphasis is on immediate support for situational awareness-building aspects in real life production environments. The coordination and collaboration needs are less supported in the technology used in our case companies. The more interesting discussion is on the introduction of individualized technology in the workplace. Several of the technology cases, has taken up smart watches and individual tablets. The extreme of this trend is the introduction of head-mounted computers (e.g. HoloLens). All of these convey information and foster an individual interaction. This is an interesting conflict with the principle of visual control ("mieruka" in Toyota parlance), wherein the concept of transparency and visibility strengthens the control aspect. This is very similar to experiences in software for office workers, where the technology is by design mostly individual. In contrast to collaborative-by-design technology such as physical status indicators on a shop floor; individualized technology needs software to aid coordination and collaboration. Future research will focus on wider adoption of the digital technologies to enhance the SA of manufacturing operators in consideration with the human factors, as well as will address the individual and collaborative SA concepts.

Table 1. Summary of case examples

\begin{tabular}{|c|c|c|c|c|c|}
\hline Support & Perception & $\begin{array}{l}\text { Comprehen- } \\
\text { sion }\end{array}$ & Projection & Coordination & $\begin{array}{l}\text { Collab- } \\
\text { oration }\end{array}$ \\
\hline $\begin{array}{l}\text { Case I } \\
\text { (Tablet) }\end{array}$ & $\begin{array}{l}\text { Machine } \\
\text { status and } \\
\text { performance } \\
\text { such as sys- } \\
\text { tem failures. }\end{array}$ & $\begin{array}{l}\text { Impact on the } \\
\text { rest of the order, } \\
\text { time available to } \\
\text { perform the or- } \\
\text { der. }\end{array}$ & $\begin{array}{l}\text { Showing } \\
\text { when to } \\
\text { change tools } \\
\text { to avoid } \\
\text { production } \\
\text { failure. }\end{array}$ & $\begin{array}{l}\text { Helping opera- } \\
\text { tors work to- } \\
\text { gether towards } \\
\text { common goals } \\
\text { and assist each } \\
\text { other. }\end{array}$ & None. \\
\hline $\begin{array}{l}\text { Case II } \\
\text { (Com- } \\
\text { puter) }\end{array}$ & $\begin{array}{l}\text { Status of or- } \\
\text { ders and re- } \\
\text { sources, } \\
\text { changes in } \\
\text { orders and } \\
\text { plans. }\end{array}$ & $\begin{array}{l}\text { Possible to co- } \\
\text { ordinate be- } \\
\text { tween orders on } \\
\text { the machine }\end{array}$ & $\begin{array}{l}\text { Root-cause } \\
\text { analysis of } \\
\text { variation in } \\
\text { input/output }\end{array}$ & $\begin{array}{l}\text { Possible to co- } \\
\text { ordinate be- } \\
\text { tween orders on } \\
\text { different ma- } \\
\text { chines. }\end{array}$ & None. \\
\hline $\begin{array}{l}\text { Case III } \\
\text { (Smart } \\
\text { watch) }\end{array}$ & $\begin{array}{l}\text { Provides re- } \\
\text { mote per- } \\
\text { ception for } \\
\text { certain key } \\
\text { events. }\end{array}$ & None. & $\begin{array}{l}\text { Provides } \\
\text { temporal } \\
\text { cues for the } \\
\text { operator. }\end{array}$ & $\begin{array}{l}\text { Only self-coor- } \\
\text { dination. }\end{array}$ & None. \\
\hline $\begin{array}{l}\text { Case IV } \\
(\mathrm{KIT})\end{array}$ & $\begin{array}{l}\text { Better un- } \\
\text { derstanding } \\
\text { of the work } \\
\text { context, } \\
\text { through } \\
\text { sensed envi- } \\
\text { ronment. }\end{array}$ & $\begin{array}{l}\text { The reasoning } \\
\text { modules allow } \\
\text { KIT to decide } \\
\text { when the opera- } \\
\text { tor is in need of } \\
\text { cognitive sup- } \\
\text { port. }\end{array}$ & $\begin{array}{l}\text { Insight into } \\
\text { upcoming } \\
\text { steps in the } \\
\text { process. }\end{array}$ & $\begin{array}{l}\text { With contextual } \\
\text { information, SA } \\
\text { in a team of op- } \\
\text { erators is im- } \\
\text { proved even if } \\
\text { just one is using } \\
\text { the device. }\end{array}$ & $\begin{array}{l}\text { Collab- } \\
\text { orative } \\
\text { work- } \\
\text { place } \\
\text { optimi- } \\
\text { zation. }\end{array}$ \\
\hline
\end{tabular}




\section{References}

1. Arica, E., Haskins, C., Strandhagen, J.O.: A framework for production rescheduling in sociotechnical manufacturing environments. Production Planning \& Control 27(14), 1191-1205 (2016).

2. Lall, M., Torvatn, H., Amdahl Seim, E.: Towards Industry 4.0: Increased Need for Situational Awareness on the Shop Floor. In: Lödding, H., Riedel, R., Thoben, K.-D., von Cieminski, G., Kiritsis, D. (eds.) Advances in Production Management Systems 2017, pp. 322-329, Springer (2017).

3. Endsley, M.R., Garland, D. J.: Situation awareness : analysis and measurement. 1st edn. Lawrence Erlbaum Associates, New Jersey (2000).

4. Endsley, M.R.: Toward a Theory of Situation Awareness in Dynamic Systems. Human Factors: The Journal of the Human Factors and Ergonomics Society 37(1), 32-64 (2016).

5. Gutwin, C., Greenberg, S.: A Descriptive Framework of Workspace Awareness for RealTime Groupware. Computer Supported Cooperative Work 11, 411-446 (2002).

6. Endsley, M.R.: Designing for Situation Awareness: An Approach to User-Centered Design. 2nd edn. CRC Press (2011).

7. Schmidt, K.: The Problem with 'Awareness': Introductory Remarks on 'Awareness in CSCW'. Computer Supported Cooperative Work (CSCW) 11(3-4), 285-298 (2002).

8. Endsley, M.R., Kiris, E.O.: The out-of-the-loop performance problem and level of control in automation. Human Factors: The Journal of the Human Factors and Ergonomics Society 37 (2), 381-394 (1995).

9. Lorenz, B., Parasuraman, R.:Automated and interactive real-time systems. Handbook of applied cognition, 415-441 (2007).

10.Holm, M.: The future shop-floor operators, demands, requirements and interpretations. Journal of Manufacturing Systems 47, 35-42 (2018).

11.Endsley, M.R., Bolstad, C. A., Jones, D. G., Jennifer, M. R.: Situation awareness oriented design: from user's cognitive requirements to creating effective supporting technologies. In Proceedings of the Human Factors and Ergonomics Society Annual Meeting. SAGE Publications Sage CA, Los Angeles, CA (2003).

12.Dhuieb, M.A., Laroche, F., Bernard, A.: Context-awareness: A Key Enabler for Ubiquitous Access to Manufacturing Knowledge. Procedia CIRP 41, 484-489 (2016).

13.El Kadiri, S., Grabot, B., Thoben, K.-D., Hribernik, K., Emmanouilidis, C., Von Cieminski, G., Kiritsis, D.: Current trends on ICT technologies for enterprise information systems. Computers in Industry 79, 14-33 (2016).

14.Shewhart, W.A., Deming, W.E.: Statistical method from the viewpoint of quality control. Courier Corporation (1986).

15.Park, C. Y., Laskey, K. B., Salim, S., Lee, J. Y.: Predictive situation awareness model for smart manufacturing. In Proceedings of the 20th International IEEE Conference on Information Fusion (Fusion). 1-8 (2017).

16.Malone, T.W., Crowston, K.: The interdisciplinary study of coordination. ACM Computing Surveys (CSUR) 26(1), 87-119 (1994).

17.Kahn, K.B., Mentzer, J.T.: Logistics and interdepartmental integration. International Journal of Physical Distribution \& Logistics Management 26(8) 6-14 (1996).

18.Bernard, S., Cauvin, A., Carver, E., Noblet, L.: The importance of situation awareness in efficiency of distributed collaborative working. In the Proceedings of the 7th International IEEE Conference on Computer Supported Cooperative Work in Design (2002).

19.Gamme, I., Seim, E. A., Lodgaard, E., Andersen, B.: Operational integration in a craftoriented small enterprise. The TQM Journal 29(2), 240-256 (2017). 